SANTIAGO GUIJARRO OPORTO

\title{
EL IMPULSO CREATIVO DE LA MEMORIA DE JESÚS EN LA TRADICIÓN JOÁNICA
}

En el estudio precedente (Revista Bíblica 2012 / 3-4) he tratado de identificar algunos de los indicios que revelan la existencia de una hermenéutica cristológica de los recuerdos de Jesús en la tradición sinóptica. El análisis de las modificaciones que experimentaron dichos recuerdos en las diversas fases del proceso que llevó hasta su inclusión en un relato de tipo biográfico ha mostrado que la pregunta acerca de Jesús impulsó de forma decisiva este desarrollo que culminó en la composición del evangelio según Marcos y, más tarde, de los otros dos sinópticos, que tomaron el relato marquiano como modelo.

En este segundo estudio analizaré desde la misma perspectiva el desarrollo de la tradición joánica. El evangelio según Juan, lo mismo que los demás libros sobre Jesús que fueron compuestos en los dos primeros siglos, incluidos los evangelios sinópticos, forman parte del proceso de relectura de los recuerdos sobre él que tuvo lugar después de su muerte. De hecho, en la tradición joánica no solo encontramos episodios que narran los sinópticos (Jesús en el templo, multiplicación de los panes, relato de la pasión, etc.), sino también otros que se parecen mucho a ellos (bodas de Caná, curación del ciego, etc.).

La peculiaridad de esta tradición no reside tanto en el tipo de recuerdos cuanto en la selección y en la peculiar interpretación que hicieron de ellos los grupos joánicos. Estos grupos, en efecto, se fijaron especialmente en algunas de las palabras y acciones de Jesús, y trataron de descubrir su significado más profundo. Esta actitud hermenéutica, que se traduce en una actividad consciente de interpretación de estos recuerdos, es el rasgo que mejor define el desarrollo de la memoria de Jesús en la tradición joánica.

Para estudiar el desarrollo de la tradición joánica es necesario tener antes una idea sobre el proceso que siguió dicha tradición hasta cristalizar 
en el evangelio según Juan. En el fondo, dicho proceso no es muy diferente al que siguieron los sinópticos. En él podemos identificar tres momentos bien diferenciados: a) el de las tradiciones y composiciones; b) el de la composición del evangelio joánico; c) el de la reelaboración de dicho evangelio ${ }^{1}$.

En la primera fase de este proceso, el tipo de interpretación que se hace de los recuerdos de Jesús es muy similar al que encontramos en la tradición sinóptica. En la segunda, sin embargo, se encuentran los elementos más característicos de la hermenéutica joánica de la memoria de Jesús. En ella vemos emerger de repente una forma de interpretar dichos recuerdos que es del todo peculiar. Lo más probable es que esta actitud hermenéutica se haya cultivado desde muy pronto en algunas de las comunidades joánicas, pero es en este momento cuando se manifiesta. Fue en esta segunda fase cuando se articularon las tradiciones anteriores en el marco de un relato de carácter biográfico (imitando probablemente a Marcos). Este relato biográfico tiene, sin embargo, un peculiar comienzo, que ofrece una clave de lectura desde la que los recuerdos sobre Jesús adquieren un nuevo y más profundo sentido.

En la tercera fase, en fin, el evangelio joánico se convirtió en el cuarto evangelio, pues, gracias a la reelaboración realizada en ella, dicho evangelio pasó a formar parte, junto con los tres sinópticos, del evangelio tetramorfo. El dato más evidente de dicha reelaboración es la inclusión del cap. 21, aunque es posible que también en esta fase se hayan incluido los caps. 15-17, así como algunas modificaciones menores ${ }^{2}$.

En este estudio me centraré en tres momentos de este proceso. En primer lugar estudiaré brevemente una de las fuentes anteriores al evangelio: la llamada Fuente de los signos, donde encontramos un tipo de hermenéutica muy parecida a la de los sinópticos. En segundo lugar trataré de esclarecer cuáles fueron las claves de la peculiar actitud hermenéutica que se manifiesta en la redacción del evangelio joánico. Por último explicitaré algunas de las claves de la relectura que se hicieron del relato de la vida de Jesús a partir del prólogo. Estos tres aspectos nos permitirán hacernos una idea del desarrollo de la tradición sobre Jesús en los círculos joánicos ${ }^{3}$.

1 Una exposición más matizada de este proceso de formación puede verse en: S. Guijarro, Los cuatro evangelios. Salamanca, Sígueme, ${ }^{2} 2012$, pp. 445-466.

2 lbid., pp. 454-455.

3 En el apartado primero retomo algunas reflexiones ya publicadas en S. GuIJARRO, «La orientación cristológica de la tradición sobre Jesús», en Estudios Eclesiásticos 85 (2010), pp. 287-308 (299-300). Los dos siguientes son una reformulación de lo que ya escribí en S. GUIJARRO OPORTO, «La relectura joánica de la tradición sobre 


\section{La Fuente de los signos}

A pesar de que solo contamos con el evangelio según Juan para reconstruirla, la existencia de esta fuente no ha sido seriamente cuestiona$\mathrm{da}^{4}$. Era una composición relativamente breve, cuyo contenido básico eran los siete relatos de milagro narrados en Jn 2-12, aunque también incluía una introducción narrativa (Jn 1,19-50) y una breve conclusión, que ahora se encuentra al final del evangelio de Juan (Jn 20,30-31). Al igual que el Relato de la pasión, era una composición eminentemente narrativa, pero, a diferencia de él, no se centraba en un momento concreto de la vida de Jesús, sino en una actividad específica, sus milagros, a los que se daba un valor especial.

La orientación de esta composición se percibe claramente en su conclusión, que decía así: «Estos [signos] se han escrito para que creáis que Jesús es el Mesías, el Hijo de Dios» (Jn 20,31). La perspectiva desde la que se contemplan en ella las acciones portentosas de Jesús es su condición de signos, que deben llevar a descubrir su verdadera identidad. Esta orientación cristológica de la composición está presente desde el comienzo. Ya en la primera escena, Juan Bautista declara abiertamente ante los enviados de los fariseos que él no es el Mesías, ni Elías, ni el Profeta, suscitando así una pregunta que se va respondiendo a medida que Jesús se va encontrando con sus primeros discípulos: «Hemos encontrado al Mesías» (Jn 1,41); «Hemos encontrado a Elías» (Jn 1,43) ; «Aquel de quien habló Moisés en la Ley y los Profetas lo hemos encontrado: Jesús, el hijo de José, de Nazaret» (Jn 1,45). Jesús, no el Bautista, es quien cumple todas estas expectativas que resumen la esperanza de Israel. En estas mismas escenas iniciales de la

Jesús», en A. Rodríguez Carmona (ed.), «Como yo os he amado» (Jn 13,34). Miscelánea sobre escritos joánicos. Homenaje a Francisco Contreras Molina, CMF. Estella, Verbo Divino, 2011, pp. 373-391, 374-377 y 386-391.

4 Además de la obra fundamental de R. T. Fortna, The Gospel of Signs: A Reconstruction of the Narrative Source Underlying the Fourth Gospel. London, 1970, cf. W. Nicol, The Semeia in the Fourth Gospel. Leiden, 1972; y sobre todo la evaluación que hace de esta hipótesis G. van BelLe, The Signs Source in the Fourth Gospel: Historical Survey and Critical Evaluation of the Semeia Hypothesis. Louvain, 1994.

${ }^{5}$ Esta identificación de Jesús con Elías no se encuentra en la actual redacción del evangelio de Juan, pero como ya mostró de forma convincente J. L. Martyn, esta ausencia se debe a la modificación de Jn 1,43 realizada por el redactor del evangelio a causa de los problemas que esta identificación creaba en el contexto de su visión de Jesús; cf. J. L. MARTYN, «We Have Found Elijah», en R. Hammerton-Kelly / R. Scroggs, (eds.), Jews, Greeks and Christians. Religious Cultures in Late Antiquity. Leiden, 1976, pp. 181-219. 
Fuente de los signos, Natanael, uno de los nuevos discípulos, añade a los títulos de carácter mesiánico la confesión de que Jesús es el Hijo de Dios (Jn 1,49), creando así una inclusión entre la introducción narrativa y la conclusión, que da a todo el conjunto una clara orientación cristológica.

Esta es, en efecto, la perspectiva desde la que deben ser leídos los signos, que evocan de diversos modos las afirmaciones que se hacen al comienzo sobre Jesús. En el segundo de ellos, el de la sanación del hijo del funcionario real, Jesús repite las palabras que Elías le dice a la viuda después de devolverle a su hijo: «iTu hijo vive!» (Jn 4,50, en alusión a 1 Re 17,23); y en el relato de la multiplicación de los panes, la gente, al ver el signo que Jesús ha realizado, exclama: «Este es verdaderamente el profeta que tenía que venir al mundo» (Jn 6,14, en alusión a Dt 18,15). En la Fuente de los signos, los milagros habían dejado de ser una prueba de que el reinado de Dios había comenzado a llegar, y se habían convertido en signos que tenían la finalidad de desvelar la identidad de Jesús como Mesías e Hijo de Dios ${ }^{6}$.

La Fuente de los signos, lo mismo que el Relato de la pasión, que examinamos al estudiar la tradición sinóptica, refleja un interés claro por la identidad de Jesús. Aunque este interés se hallaba ya presente en las unidades de la tradición oral a partir de las que fue formada (chreias y relatos de milagro, principalmente), la composición de este relato más elaborado refleja una situación en que dicho interés se había acrecentado. Por otro lado, también en este relato se recurre a la memoria cultural de Israel para mostrar quién es Jesús. Y así, mientras el relato tradicional de la pasión identificaba a Jesús con la figura del justo sufriente, en la Fuente de los signos son las figuras mesiánicas las que ocupan el primer plano. Estas semejanzas confirman que las raíces de la tradición joánica se encuentran en ese fondo común de memoria compartida sobre Jesús en el que también hay que situar los orígenes de la tradición sinóptica.

\section{Una nueva hermenéutica de los recuerdos de Jesús}

Aunque la Fuente de los signos refleja un tipo de hermenéutica de los recuerdos sobre Jesús que es muy similar a la que encontramos en la tradición sinóptica, la interpretación de las palabras y acciones de Jesús

- Sobre la evolución del significado de los milagros de Jesús en la tradición joánica, véase el excelente estudio de H. WEDER, «Von der Wende der Welt zum Semeion des Sohnes», en A. Denaux (ed.), John and the Synoptics. Leuven, 1992, pp. 127-145. 
que aparece de forma más visible en el evangelio según Juan es muy diferente. Comparada con la interpretación sinóptica, esta hermenéutica joánica se caracteriza por un tipo de comentario que integra explícitamente la perspectiva pospascual. Este tipo de interpretación revela una actitud «derásica» que tiene su origen, muy probablemente, en el hábito de comentar la Escritura ${ }^{7}$.

Como ejemplo de esta actitud y de los procedimientos a los que recurre puede citarse el episodio del templo, que Juan, a diferencia de los sinópticos, sitúa al comienzo de su relato. En este pasaje, el narrador le aclara al lector que los discípulos comprendieron el sentido de aquel gesto de Jesús y de las palabras que entonces pronunció a través de un progresivo acto de recuerdo: primero recordaron las Escrituras, las cuales les ayudaron a comprender el sentido de la acción realizada por Jesús (Jn 2,17). Después recordaron las palabras de Jesús, cuyo sentido profundo solo pudieron comprender después de su resurrección (Jn 2,22) ${ }^{8}$. Esta última aclaración del narrador es muy importante, porque en el evangelio según Juan es después de la resurrección cuando los discípulos reciben el Espíritu (Jn 7,39; 20,22) ${ }^{9}$.

En la tradición joánica, la verdadera interpretación de las palabras y de las acciones de Jesús, es decir, aquella que lleva a comprender lo que estas palabras y acciones revelan acerca de él (en este caso, que el templo del que hablaba era su cuerpo), es la que se hace bajo la acción del Espíritu. Esta forma de recordarlas es la que despierta la fe: «Creyeron en la Escritura y en la palabra que había dicho Jesús» (Jn 2,22). No se trata, pues, de un recuerdo neutro que deja los acontecimientos en el pasado, sino de una forma de memoria que tiene relevancia para el presente y suscita la fe. Este tipo de comentario que actualiza el sentido de un texto o, como en este caso, de un recuerdo que se interpreta a la luz de la Escritura es propio de la actitud derásica.

La clave para comprender esta forma de interpretar las palabras y acciones de Jesús se encuentra en el gran discurso de despedida, que Juan sitúa en la última cena de Jesús con sus discípulos, especialmente en los llamados anuncios del Paráclito. Estos anuncios evocan la acción del Espí-

7 Sobre el derás y su relación con otras formas de comentario, cf. D. MuÑoz LEón, Derás. Los caminos y sentidos de la palabra divina en la Escritura. Madrid, 1987, pp. 19-28.

8 Cf. M. PEsCE, «La trasmissione delle parole di Gesù», en M. PESCE, Da Gesù al cristianesimo. Brescia, 2011, pp. 35-54 (44-45).

9 En varios lugares del evangelio de Juan se habla de esta comprensión pospacual: además del episodio citado: Jn 12,16; 13,7; 20,9, que coincide con el don del Espíritu. 
ritu en el período pospascual. Dicha acción consistirá sobre todo en una forma de recuerdo que llevará a los discípulos a una mayor comprensión: «Él [el Paráclito] os enseñará todo y os recordará todas las cosas que os he dicho» (Jn 14,26).

Los dos primeros anuncios, que se encuentran en el diálogo/simposio que sigue al lavatorio de los pies (Jn 13,31-15,41), se diferencian de los tres que se encuentran en el discurso siguiente (Jn 15,1-16,33). Los dos primeros se refieren a la acción del Espíritu con respecto a las palabras de Jesús, mientras que los tres últimos se centran en su papel con respecto al mismo Jesús. En cualquier caso, una lectura de los cinco anuncios descubre la dimensión hermenéutica de la acción del Espíritu y su principal finalidad.

En el primero de ellos (Jn 14,16-17) se anuncia tan solo que el Paráclito permanecerá con los discípulos para siempre. En el segundo (Jn 14,25-26), sin embargo, se insiste en las funciones anamnética y didáctica mencionadas más arriba. Ambas funciones están relacionadas entre sí. Gracias al recuerdo, las palabras pronunciadas por Jesús en el pasado pueden seguir resonando en el presente. Pero este recuerdo no será una simple repetición, sino que irá acompañado por una enseñanza que incluirá una interpretación de las mismas. De esta forma, la memoria de Jesús, transmitida por los que fueron testigos de sus acciones y de sus enseñanzas, podrá tener sentido y vigencia para una nueva época y para una nueva situación. La función del Paráclito será, por tanto, actualizar constantemente el testimonio sobre Jesús ${ }^{10}$.

En los tres anuncios siguientes, los verbos que describen las funciones del Paráclito muestran que estas tienen que ver sobre todo con la adecuada comprensión de la identidad de Jesús ${ }^{11}$. Estas funciones aparecen principalmente en el tercer anuncio y en el quinto, y consisten en dar testimonio sobre Jesús, conducir a los discípulos hasta la verdad plena y glorificar a Jesús (Jn 15,26; 16,12.14). Estas tres funciones presuponen una progresión en el conocimiento de Jesús. Al afirmar que el Espíritu conducirá a los discípulos hasta la verdad plena se presupone un proceso, cuyo punto

${ }^{10} \mathrm{Cf}$. a este respecto las reflexiones de U. SCHNELLE, «Johannes als Geisttheologe», en Novum Testamentum 40 (1998), pp. 17-31 (18-22), que sitúa esta función hermenéutica del Espíritu en el marco de la pneumatología joánica.

11 F. Mussner, «Die johanneische Parakletsprüche und die apostoslische Tratition», en Biblische Zeistschrift 9 (1961), pp. 56-70 (59-64), estudió estas funciones observando que la mayoría de ellas tienen que ver con la tradición sobre Jesús, pero no advirtió la diferencia entre las dos primeras y las tres últimas ni tampoco el significado de la progresiva concentración en la figura de Jesús. 
de partida es un conocimiento parcial o imperfecto de dicha verdad. Ahora bien, en el evangelio de Juan, la verdad que se revela es el mismo Jesús (Jn $1,14 ; 14,6)$. La función del Espíritu será conducir a los discípulos hasta la plenitud de esta revelación, que solo se puede alcanzar con su ayuda. Las otras dos funciones: dar testimonio acerca de Jesús y glorificarle (manifestar o proclamar su gloria), también presuponen que los discípulos necesitan conocer más a fondo o de una manera nueva a Jesús, y que este conocimiento solo se puede alcanzar bajo la guía del Espíritu.

Lo que se dice en estos pasajes acerca de la acción del Paráclito ayuda a identificar un aspecto crucial del contexto hermenéutico en el que se conservaron y transmitieron muchas de las palabras y las acciones de Jesús recogidas en el evangelio de Juan. Este recuerdo parece haber madurado en el marco de una intensa acción del Espíritu, a quien la comunidad joánica reconocía como guía y maestro ${ }^{12}$. El estudio comparado de las religiones revela que este tipo de experiencias facilitan enormemente el desarrollo de nuevas creencias o permiten descubrir aspectos nuevos en creencias ya asentadas ${ }^{13}$. Y esto es precisamente lo que aparece en los anuncios del Paráclito, cuya acción consiste en llevar a los discípulos a una nueva comprensión de las palabras y acciones de Jesús. Este contexto de vivencia religiosa explica en parte la peculiar comprensión de la tradición sobre Jesús que encontramos en el cuarto evangelio.

Estos anuncios del Paráclito evocan el marco y el proceso que llevó a una comprensión más profunda de la tradición sobre Jesús, pero no mencionan las pautas concretas que determinaron tal desarrollo. Lo único que dicen es que la misión del Espíritu consistió en llevar a una comprensión más profunda de la identidad de Jesús. Esta indicación sugiere que dichas pautas deben buscarse en la visión de Jesús que es propia del evangelio de Juan o quizá, más precisamente, en aquellas convicciones a partir de las cuales esta se fue elaborando.

Ahora bien, en el evangelio de Juan, tal como ha llegado hasta nosotros, la imagen de Jesús se construye dialécticamente en la relación que se establece entre el prólogo y el relato que sigue. El prólogo habla de la Palabra preexistente (Lógos ásarkos) y el relato de la Palabra encarnada

12 Tanto el evangelio como las cartas de Juan dan testimonio de que esta experiencia espiritual fue muy importante para aquella comunidad; cf. a este respecto J. D. G. Dunn, Jesús y el Espíritu. Un estudio de la experiencia religiosa y carismática de Jesús y de los primeros cristianos, tal como aparece en el Nuevo Testamento. Salamanca, 1981, pp. 562-574, espec. 565-568.

${ }^{13}$ Cf. L. W. Hurtado, «Religious Experience and Religious Innovation in the New Testament», en The Journal of Religion 80 (2000), pp. 183-205. 
(Lógos énsarkos), pero en ambos casos se trata del mismo Logos, cuya identidad solo se puede descubrir teniendo en cuenta ambas dimensiones. En el evangelio, esta convicción ha quedado expresada en el hecho literario de anteponer el prólogo al relato de la actividad pública de Jesús. Por eso nuestra indagación puede continuar analizando el significado y el alcance de este dato literario.

\section{La relectura a la luz del prólogo}

Al colocar el prólogo como pórtico de su obra, el autor del evangelio ha querido proponer explícitamente al Logos preexistente como clave para leer el relato en el que se narran las acciones y palabras de Jesús, el Logos encarnado. Es muy probable que la cristología que refleja el prólogo no haya sido la única ni tampoco la que más influyó en la relectura de la tradición sobre Jesús. De hecho, existe una tensión entre dicha cristología, que se concentra en la preexistencia del Logos y posee un esquema puramente descendente (el Logos se hizo carne), y varios pasajes del relato, en los que domina un esquema que incluye el descenso y el ascenso. Este esquema (Jesús como enviado del Padre, que volverá a él a través de su muerte-glorificación) es probablemente anterior a la cristología del prólogo y tuvo un influjo determinante en la relectura de los recuerdos sobre Jesús, como se advierte, por ejemplo, en Jn $6^{14}$.

Sin embargo, el redactor final eligió la cristología del prólogo como clave para la lectura de su relato. Por eso quisiera mostrar ahora con algunos ejemplos cómo la cristología del Logos influyó en la relectura de la tradición sobre Jesús. Lo característico de esta visión de Jesús, como ya hemos dicho, es que el Logos preexistente, su condición, cualidades, forma de actuar, etc., se propone como clave para comprender las acciones, las palabras y el destino del Logos encarnado. Dado que no es posible analizar todo el evangelio en los límites de este estudio, me centraré en la interpretación de algunos de los milagros de Jesús.

Antes de ser incorporados al evangelio de Juan, como ya hemos visto, estos recuerdos formaban parte de la Fuente de los signos. Al ser incorporados al evangelio, estos signos fueron ligeramente retocados en su redacción, y algunos de ellos, principalmente los que se encuentran en la

${ }^{14}$ Así lo mostró el excelente estudio de P. Borgen, Bread from Heaven. An Exegetical Study of the Concept of Manna in the Gospel of John and the Writings of Philo. Leiden, 1965, pp. 158-165. 
sección más polémica de la actuación de Jesús (Jn 5-10), fueron comentados por medio de amplios diálogos y discursos, en los que se desvela su sentido más profundo. Es en estos diálogos y discursos donde se encuentran algunas alusiones a la cristología del prólogo que revelan su influjo en el proceso de relectura de la tradición sobre Jesús.

En la primera parte del discurso que sigue a la curación del paralítico en la piscina de Betesda (Jn 5,17-30) se pueden identificar ya algunas de estas alusiones. A la acusación de haber realizado la curación en sábado Jesús responde: «Mi Padre sigue trabajando hasta ahora y yo también trabajo» (Jn 5,17). Esta afirmación debe entenderse en el contexto de las discusiones judías sobre si Dios podía o no descansar en sábado (Gn 2,2-3). La opinión más común era que Dios debía seguir realizando algunas funciones, como dar la vida a los que nacen o juzgar a los que mueren ${ }^{15}$. Al afirmar que la curación realizada se inscribe en esta creación continuada, Jesús se está identificando con Dios, como de hecho reconocen enseguida sus interlocutores: «Llama padre suyo a Dios, haciéndose igual a Dios» (Jn 5,18). Esta asociación de Jesús con Dios en la acción de seguir dando vida (Jn 5,21) evoca la participación del Logos en la creación inicial: «Todo fue hecho por medio de él, y nada existió sin él» (Jn 1,3; cf. Jn 1,10), mientras que su identificación con Dios recuerda la afirmación inicial del prólogo: «El Logos era Dios» (Jn 1,1). Tanto en el prólogo como en el discurso, la identificación del Logos-Jesús con Dios tiene como consecuencia el hecho de dar vida: «En él había vida» (Jn 1,4) = «Así como el Padre tiene vida en él, así también le concedió al Hijo tener vida en él» (Jn 5,26). Esta cualidad de Jesús, que aparece de diversas formas en el evangelio, sobre todo en el discurso del pan de vida (Jn 6,28-51), culminará en la afirmación de Jn 11,25: «Yo soy la resurrección y la vida» (cf. también Jn 14,6).

El segundo signo narrado en esta sección es la multiplicación de los panes (Jn 6,1-15). En Juan, como en la tradición anterior, este milagro va unido al de la travesía del lago (cf. Mc 6,32-51). Sin embargo, el discurso que sigue comenta solo el primero de estos dos signos. Como ya mostró P. Borgen, este discurso está construido a partir de técnicas derásicas que también se utilizan en el prólogo ${ }^{16}$. Sin embargo, desde el punto de vista del contenido, el discurso presupone ante todo la cristología del descensoascenso, que tiene como trasfondo la institución jurídica del «agente»: Jesús, como enviado de Dios, es el verdadero pan del cielo y es capaz de dar

15 Cf. P. Borgen, «Logos Was the True Light: Contributions to the Interpretation of the Prologue of John», en Novum Testamentum 14 (1972), pp. 115-130 (120).

16 Cf. P. Borgen, Bread from Heaven, o. c., pp. 59-98. 
la vida al mundo (Jn 6,33). Con todo, la insistencia en el movimiento de descenso y en la capacidad de dar vida evoca de nuevo lo que se dice en el prólogo acerca del Logos preexistente: «En él había vida» (Jn 1,4). A lo largo del discurso se encuentra también un comentario que alude inequívocamente al prólogo: «Nadie ha visto al Padre a no ser el que estaba junto a Dios» (Jn 6,46). La expresión «el que estaba junto a Dios» (ho ôn para tou theou) es una alusión clara a lo que se dice del Logos en Jn 1,1: «El Logos estaba vuelto hacia Dios» (ho logos ên pros ton theon). Aunque se trata de un inciso aclaratorio, que pudo haber sido añadido en una fase tardía de la elaboración del este discurso, esta alusión indica que el prólogo influyó en la relectura de la tradición sobre Jesús.

Finalmente, en el último de los signos narrados en Jn 5-10, la curación del ciego de nacimiento (Jn 9,1-7), la cristología del prólogo ha motivado una interpretación del relato tradicional, en el que se ha introducido un comentario aclaratorio que dice así: «Nosotros tenemos que realizar las obras del que me ha enviado mientras es de día; vendrá la noche y entonces nadie podrá realizarlas; mientras estoy en el mundo, soy la luz del mundo» (Jn 9,4-5). La identificación de Jesús como luz es un tema que atraviesa todo el evangelio. Ya en el diálogo con Nicodemo, el narrador evoca la afirmación del prólogo: «La luz brilla en la tiniebla, pero la tiniebla no la recibió» (Jn 1,5; cf. Jn 3,19). Más adelante, Jesús se identifica a sí mismo como la «la luz del mundo» (Jn 8,12), evocando así otra de las afirmaciones del prólogo: «Él [el Logos] era la luz verdadera... que ha venido al mundo» (Jn 1,9). Es interesante observar que esta afirmación desencadena una amplia discusión acerca del origen de Jesús y su relación con el Padre (Jn 8,12-59). En este contexto, la curación del ciego de nacimiento se convierte en una confirmación de que Jesús, efectivamente, es el Logos encarnado, cuya actuación terrena es un reflejo de su actuación como Logos preexistente.

Estas breves anotaciones sobre las alusiones a la cristología del prólogo que han sido introducidas en el proceso de relectura de algunos de los signos muestran cómo esta visión de Jesús que domina la obra final pudo haber influido en el proceso de memoria y relectura de la tradición realizada en el seno de las comunidades joánicas. Aunque las alusiones más directas se encuentran en comentarios que muy bien podrían haber sido introducidos en los estadios tardíos de la composición del evangelio, otras sugieren que la cristología del prólogo influyó también en el proceso de transmisión e interpretación de dicha tradición.

Esta forma de interpretar los milagros de Jesús es ciertamente posterior a la composición de la Fuente de los signos, en la cual no se encontra- 
ban los diálogos y discursos que ahora acompañan a los signos. La cristología de esta fuente era, como hemos visto, mucho más cercana a la de los sinópticos y se asentaba sobre dos afirmaciones básicas: Jesús es el Mesías, el Hijo de Dios (Jn 20,31). El influjo de la cristología más típicamente joánica (descenso-ascenso, preexistencia, etc.) en la interpretación de la tradición sobre Jesús hay que atribuírsela a un grupo diferente del que transmitió la Fuente de los signos. Esta conclusión confirma la impresión de que la comunidad joánica fue, en realidad, el resultado de la fusión de diversos grupos de discípulos de Jesús que tenían sensibilidades distintas. Aquel en el que maduró la interpretación que se inspira en la cristología más característicamente joánica practicaba un tipo de exégesis que aparece por doquier en los diálogos y en los discursos de Jesús, y que también se puede observar en el prólogo ${ }^{17}$. Fue este grupo el que releyó la tradición sobre Jesús desde una cristología alta, que finalmente fue asumida por la mayoría de los grupos joánicos. La composición del evangelio, en el que la contemplación del Logos preexistente se propone como clave para leer la biografía del Logos encarnado, tuvo en ello un papel fundamental.

\section{Conclusión}

La cuestión de fondo que he pretendido plantear en este estudio podría formularse así: ¿cuáles fueron los factores que determinaron la forma de recordar e interpretar dichos recuerdos en el seno de las comunidades joánicas? En él he analizado algunos textos que reflejan diversas formas de recordar e interpretar los recuerdos sobre Jesús. Aquí aparece de forma aún más clara que en la tradición sinóptica que tales recuerdos fueron continuamente interpretados. También aparece en este caso con más claridad que dicha interpretación fue el resultado de una búsqueda: aquella que trataba de responder a la pregunta por la identidad de Jesús.

En el caso de la Fuente de los signos, esta búsqueda y la hermenéutica que la acompañó fueron muy similares a las que hemos identificado en la tradición sinóptica. Seguramente puede decirse lo mismo de la otra gran fuente, también narrativa, que utilizó el autor del evangelio joánico: el Relato de la pasión. Sin embargo, en el momento de la composición del evangelio nos hemos encontrado con otras formas de interpretar aquellos recuerdos. De hecho, fue esta nueva hermenéutica la que acabó imponiéndose en

17 P. Borgen, «Logos Was True Light», o. c., y D. Boyarin, The Gospel of the Memra, han insistido especialmente en este aspecto. 
la tradición joánica. El tipo de interpretación de las palabras y de las acciones de Jesús que se percibe en esta «hermenéutica joánica» no es homogéneo, pues se inspira en diversos esquemas teológicos. Sin embargo posee algunos rasgos comunes que merece la pena resaltar.

El análisis de los anuncios del Paráclito ha abierto el camino para identificar el primero de ellos: la importancia decisiva de una experiencia religiosa viva en la relectura de la tradición. Se trataba obviamente de una experiencia comunitaria, como revela el uso de la segunda persona del plural en dichos anuncios. Esta experiencia de contacto directo con la divinidad a través de la actuación del Espíritu posibilitó una interpretación abierta de las palabras y de las acciones de Jesús, y legitimó los nuevos sentidos que se descubrían en ellas.

El segundo rasgo, relacionado con el precedente, fue la intensa elaboración cristológica que se dio en el seno de algunos grupos joánicos. La comprensión cada vez más plena de la identidad, el origen y la misión de Jesús fueron un factor determinante en la relectura joánica de la tradición sobre él. Aunque resulta difícil precisar qué es lo que dio lugar a la cristología alta que caracteriza esta visión, no sería aventurado suponer que esta se fue construyendo a partir de diversos elementos. Uno de ellos fue sin duda la reflexión sobre el sentido de sus dichos y sus acciones, que aparece en afirmaciones como la que Juan pone en boca de Nicodemo: «Maestro, sabemos que has venido de Dios como maestro, pues nadie puede hacer los signos que tú haces si Dios no está con él» (Jn 3,2). Pero también debieron de influir las reflexiones y comentarios que se hacían en algunos grupos judíos acerca de Dios y su comunicación con los seres humanos a través de la Ley o la Sabiduría. Fue en esta relación dialéctica con un entorno creativo como se llegó a elaborar la cristología alta desde la que se releyó la tradición de los dichos y las acciones de Jesús.

La aplicación de estas dos claves a la relectura de la tradición sobre Jesús se vio enormemente favorecida por un recurso común en el entorno de los grupos joánicos: el comentario derásico, que estos últimos aplicaron no solo a los textos de la Escritura, sino también a las palabras y acciones de Jesús. Estos factores parecen haber determinado la relectura de estos recuerdos en la tradición joánica con el paso del tiempo, pues en la comunidad joánica tuvo lugar un proceso en el que poco a poco los diversos grupos que la formaban fueron aceptando esta relectura que finalmente dio como resultado el evangelio según Juan.

SAntiago Guijarro Oporto

Salamanca, España 